\title{
Synthesis and characterization of CdS nanorods by combined sonochemical-solvothermal method
}

\author{
Pinar ACAR BozKurT*, Burak DERKuş \\ Department of Chemistry, Science Faculty, Ankara University Ankara, Turkey
}

\begin{abstract}
Cadmium sulfide (CdS) nanorods with a diameter of $50 \mathrm{~nm}$ and length of approximately $200 \mathrm{~nm}$ have been synthesized using combined sonochemical-solvothermal method. Structural properties of CdS nanoparticles synthesized by this method have been compared with the CdS nanoparticles synthesized by sonochemical method alone. The synthesized CdS nanostructures have been characterized using X-ray diffraction (XRD), energy dispersive X-ray spectroscopy (EDX) and transmission electron microscopy (TEM) methods. In addition, the factors affecting the formation of the structures, including reaction time, different type and ratio of precursors, such as sulphur source, have been investigated. Comparison of the results obtained by both the synthesis methods revealed CdS nanoparticles synthesized by the combined sonochemical-solvothermal method to be of high morphological homogeneity compared to the sonochemical method alone. It is interesting to note that ethylenediamine has been found to be prevented from agglomeration by using the combined sonochemical-solvothermal method as the synthesis method. A modified growth mechanism under the inducement of ethylenediamine solutions for the CdS nanorods has been suggested.
\end{abstract}

Keywords: nanorods; semiconductor; sonochemical-solvothermal method; characterization

(C) Wroclaw University of Technology.

\section{Introduction}

Nanoparticles and nanostructural materials have attracted considerable interest in recent years. These materials have found extensive use in various fields such as high density memory devices, lasers, transistors and other optoelectronic systems [1-3].

When approaching the nanoscale dimension particle size, some material characteristics are seen to vary considerably. For example, electrical conductivity exhibits non-ohmic behavior and staircase-like current voltage curves are observed. The materials also show conduction properties between superconductors and insulators. In addition, the relevant excitonic peak shifts to higher energy values. This property allows tuning the band gap by adjusting the particle size. This electronic transition behavior has been coined as the quantum confinement effect [4].

Among semiconductor nanoparticles derived from group II - VI elements, CdS is the most interesting due to its unique electrical and optical

*E-mail: p3acar@hotmail.com properties which have led to its intensive applications in photo catalysis and photoconduction cells [5-7]. Especially the particle size dependency of these properties has led to several efforts being extended towards the synthesis of smaller sized particles.

CdS nanostructures have been synthesized using different approaches including solvothermal or hydrothermal methods [8,9], thermal evaporation [10], chemical vapor approach [11] and electrochemical deposition $[12,13]$. Amongst them the solvothermal method is the highest yield and the most easily controlled method for the synthesis of $\mathrm{CdS}$ nanoparticles.

In recent years, the sonochemical method has proven to be a beneficial technique for synthesizing novel materials. The chemical effects of ultrasound arise from acoustic cavitation, which involves the formation, growth, and implosive collapse of bubbles in liquid which generate transient temperatures up to $\sim 5000 \mathrm{~K}$, pressure of $\sim 1800 \mathrm{MPa}$ and cooling rate in excess of $10^{10} \mathrm{~K} / \mathrm{s}$ [14]. This method is a subject of fast-growing research owing to some advantages such as rapid reaction rates, 
controllable reaction conditions and the ability to form nanoparticles with high purity [15]. Therefore, this method has been extensively used for the synthesis of various nanostructured materials [16-18]. Both the sonochemical and solvothermal methods are effective in the synthesis of nanoparticles.

In this study, structural properties of $\mathrm{CdS}$ nanoparticles synthesized by the combined sonochemical-solvothermal method have been compared with the results of sonochemical method. In addition, the effects of reaction time, type and ratio of precursor, such as sulphur source, on the morphology and particle size of $\mathrm{CdS}$ nanoparticles have been evaluated. We used the combined sonochemical-solvothermal method in order to synthesize hexagonal phase $\mathrm{CdS}$ nanoparticles with high morphological homogeneity. The formation mechanism of hexagonal $\mathrm{CdS}$ nanorods have been explained by self-assembled growth under the inducement of ethylenediamine solutions. The synthesized nanoparticles were characterized using X-ray diffraction (XRD), energy dispersive X-ray spectroscopy (EDX) and transmission electron microscopy (TEM).

\section{Experimental}

\subsection{Materials}

Analytical grade cadmium nitrate tetrahydrate $\left(\mathrm{Cd}\left(\mathrm{NO}_{3}\right)_{2} \cdot 4 \mathrm{H}_{2} \mathrm{O}\right)$, sodium sulfide $\left(\mathrm{Na}_{2} \mathrm{~S}\right)$, ethylenediamine $\left(\mathrm{NH}_{2}\left(\mathrm{CH}_{2}\right)_{2} \mathrm{NH}_{2}\right)$, ethanol and thioacetamide (TAA) from Merck have been used without further purification. Ultra-distilled water was used for sample preparation.

\subsection{Synthesis of CdS nanoparticles}

Sonochemical synthesis was carried out as described elsewhere [19]. In a typical experiment, $1 \mathrm{mmol}$ cadmium nitrate $\left(\mathrm{Cd}\left(\mathrm{NO}_{3}\right)_{2}, 0.236 \mathrm{~g}\right)$ was dissolved in $50 \mathrm{~mL}$ hot ultra-distilled water under vigorous stirring. Subsequently, 2 mmol TAA $(0.150 \mathrm{~g})$ as sulphur source in $50 \mathrm{~mL}$ water solution was slowly added dropwise into the cadmium nitrate solution. The solution was stirred continuously while the $\mathrm{pH}$ value was kept constant at 12 . Then the mixture was sonicated in the ultrasonic device (Sonics VCX 750 with an ultrasound power of $750 \mathrm{~W}$ and frequency of $20 \mathrm{kHz}$ ) to react for a given time. After the sonication process, $40 \mathrm{~mL}$ of ethanol was added to the mixture to obtain a yellowish precipitate which was separated by centrifugation. The resulting product was dried in vacuum at $70{ }^{\circ} \mathrm{C}$ for $24 \mathrm{~h}$.

The modified synthesis method is comprised of combined sonochemical and solvothermal methods. In this method $1 \mathrm{mmol}$ cadmium nitrate $\left(\mathrm{Cd}\left(\mathrm{NO}_{3}\right)_{2}, 0.236 \mathrm{~g}\right)$ was dissolved in $30 \mathrm{~mL}$ ethylenediamine under vigorous stirring with a magnetic stirrer. The sulphur source, $4 \mathrm{mmol}$ sodium sulfide $\left(\mathrm{Na}_{2} \mathrm{~S}, 0.312 \mathrm{~g}\right)$ solution, was then slowly added into this solution under continuous stirring for 30 minutes. The mixture was then sonicated in the ultrasonic device (Sonics VCX 750 with an ultrasound power of $750 \mathrm{~W}$ and frequency of $20 \mathrm{kHz}$ ) to react for a given time. After sonication, the mixture was placed into an autoclave and left for $24 \mathrm{~h}$ at $200{ }^{\circ} \mathrm{C}$. After cooling to room temperature the product was washed with ultradistilled water and ethanol several times and then filtered. The filtered product was dried under vacuum at $70{ }^{\circ} \mathrm{C}$ for $24 \mathrm{~h}$.

In order to investigate the influence of the sulphur source and reaction time on the morphologies of CdS particles, several samples were prepared under different conditions as listed in Table 1.

\subsection{Characterization of CdS nanoparti- cles}

The X-ray diffraction (XRD) patterns were measured on a Rigaku D/MAX 2200 diffractometer with $\mathrm{CuK} \alpha$ radiation $(\lambda=1.5418 \AA)$, at a scanning speed of $0.15^{\circ} / \mathrm{min}$ within the range of $2 \theta=20^{\circ}$ to $80^{\circ}$. Transmission electron microscopy (TEM) study was performed using a FEI, model Tecnai G2 F30 system operated at $100 \mathrm{kV}$ and equipped with an X-ray energy dispersive spectroscopy (EDX; model EDAX, AMETEK).

\section{Results and discussion}

Firstly, the as-synthesized CdS samples were characterized using XRD. The XRD results revealed pure $\mathrm{CdS}$ nanoparticles to be successfully 
Table 1. Effects of the experimental conditions on the structure of the CdS nanoparticles.

\begin{tabular}{ccccc}
\hline Sample & Kind of method & Composition & Reaction time & Structure \\
\hline \hline S1 & sonochemical & $\mathrm{Cd}\left(\mathrm{NO}_{3}\right)_{2}+\mathrm{TAA}(1: 2)$ & $40 \mathrm{~min}$ & cubic \\
S2 & sonochemical & $\mathrm{Cd}\left(\mathrm{NO}_{3}\right)_{2}+\mathrm{Na}_{2} \mathrm{~S}(1: 2)$ & $40 \mathrm{~min}$ & cubic \\
S3 & combined sonochemical-solvothermal & $\mathrm{Cd}\left(\mathrm{NO}_{3}\right)_{2}+\mathrm{TAA}(1: 2)$ & $40 \mathrm{~min}$ & hexagonal (irregular) \\
S4 & combined sonochemical-solvothermal & $\mathrm{Cd}\left(\mathrm{NO}_{3}\right)_{2}+\mathrm{TAA}(1: 4)$ & $1 \mathrm{~h}$ & hexagonal (irregular) \\
S5 & combined sonochemical-solvothermal & $\mathrm{Cd}\left(\mathrm{NO}_{3}\right)_{2}+\mathrm{Na}_{2} \mathrm{~S}(1: 4)$ & $1 \mathrm{~h}$ & hexagonal (irregular) \\
S6 & combined sonochemical-solvothermal & $\mathrm{Cd}\left(\mathrm{NO}_{3}\right)_{2}+\mathrm{Na}_{2} \mathrm{~S}(1: 4)$ & $5 \mathrm{~h}$ & hexagonal \\
\hline
\end{tabular}

synthesized via the sonochemical and combined sonochemical-solvothermal methods.

The X-ray diffraction patterns of CdS nanoparticles synthesized with the sonochemical method (Sample S1) are given in Fig. 1. The intense three peaks seen at angles $26.41^{\circ}, 44.05^{\circ}$ and $51.79^{\circ}$

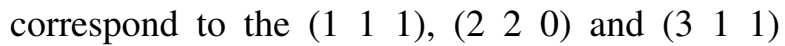
planes of $\mathrm{CdS}$, respectively. These results indicate the CdS nanoparticles to crystallize in cubic phase, which is compatible with the reported data (JCPDS Card File No. 10-454). No peaks attributed to other phases were observed. It was also determined that other CdS nanoparticles synthesized by the sonochemical method (Sample S2), crystallized in cubic phase. The X-ray diffraction patterns of this product are shown in Fig. 1a.

The X-ray diffraction patterns of CdS nanoparticles synthesized with combined sonochemicalsolvothermal method (Sample S6) are shown in Fig. 1b. The XRD patterns reveal seven peaks at angles $24.78^{\circ}, 26.46^{\circ}, 28.15^{\circ}, 36.59^{\circ}, 43.66^{\circ}$, $47.85^{\circ}$ and $52.83^{\circ}$ corresponding to the $\left(\begin{array}{lll}1 & 0 & 0\end{array}\right)$,

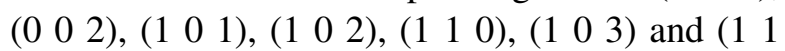
2) planes of $\mathrm{CdS}$, respectively. Existence of this set is an evidence of the hexagonal CdS structure. The XRD results are in good agreement with the reported data (JCPDS Card File, No. 41-1049). No peaks corresponding to impurities were detected. Also, it was determined that other CdS nanoparticles synthesized with combined sonochemicalsolvothermal method (Samples S3-S4-S5), crystallized in hexagonal structure. The X-ray diffraction patterns of this product are shown Fig. 1b.

The products synthesized by different methods crystallized in different symmetries; however,

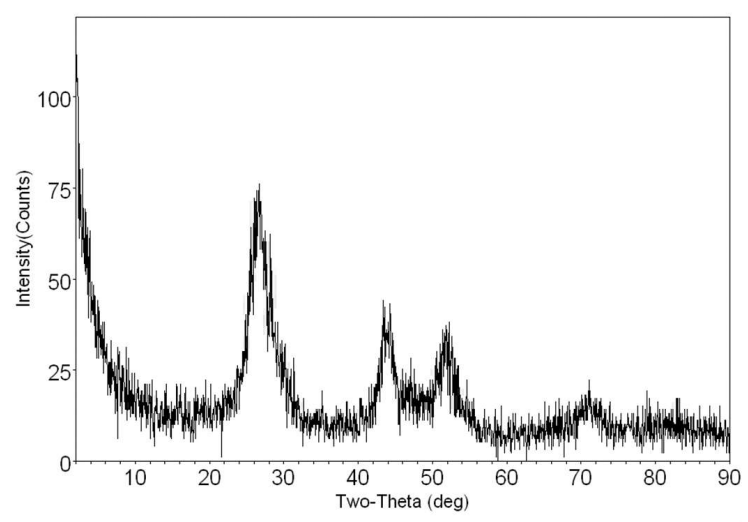

(a)

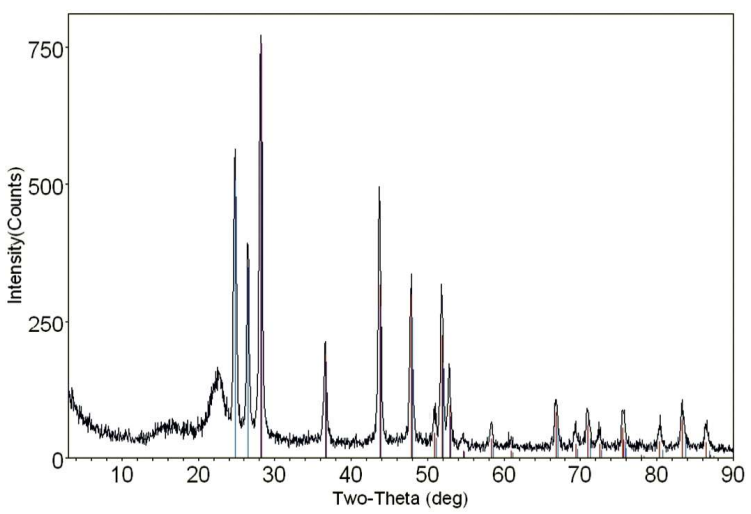

(b)

Fig. 1. XRD patterns of CdS nanoparticles synthesized by different methods (a) sonochemical method (Sample S1), (b) combined sonochemicalsolvothermal method (Sample S6).

CdS synthesized by the combined sonochemicalsolvothermal method is more amorphous in nature when compared to the $\mathrm{CdS}$ synthesized by only the sonochemical method. Comparison of the XRD results for $\mathrm{CdS}$ synthesized 
by the combined sonochemical-solvothermal method and the sonochemical method alone shows strong and sharp peaks with high intensity for the combined method, revealing a higher degree of crystallization. The influence of the synthesizing method can be observed by the fact that $\mathrm{CdS}$ synthesized by the sonochemical method has a cubic structure whereas the product obtained by combined sonochemical-solvothermal method reveals a hexagonal structure. It is obvious from the above results that the ratio of precursor, such as sulphur, source may play an important role in the structure of CdS samples in these experiments. The sample obtained at a higher $\mathrm{Cd}: \mathrm{S}$ ratio had a better crystalline structure compared to those obtained at lower ratios (Table 1). As the best results were obtained for samples S1 and S6 we have used them for further evaluation.

Higher hydrogen production rates and higher photoefficiencies have been obtained with hexagonal $\mathrm{CdS}$ phase when compared to the cubic $\mathrm{CdS}$ phase [20]. These results signify the importance of improvement of the synthesis method to obtain hexagonal $\mathrm{CdS}$ structures which seem more suitable and efficient in photocatalytic procedures. Another important parameter controlling the structure is the temperature. Cubic phase $\mathrm{CdS}$ was obtained by the sonochemical method at low temperatures, whereas hexagonal CdS structures were generally obtained at higher temperature. Therefore we can conclude that the combined sonochemicalsolvothermal method used in this study is more suitable for the synthesis of hexagonal CdS.

The morphology and nanostructure of $\mathrm{CdS}$ nanoparticles are clearly demonstrated by the TEM images given in Fig. 2. Accordingly, sonochemically synthesized CdS nanoparticles (Sample S1) are non-uniform spherical structures with a diameter of $10 \mathrm{~nm}$. The agglomerated spherical nanostructures of CdS particles are seen in Fig. 2a. $\mathrm{CdS}$ nanoparticles synthesized using the combined method (Sample S6) reveal the formation of typical nanorods with an average diameter of $50 \mathrm{~nm}$ and length of approximately $200 \mathrm{~nm}$. Unlike the particle structures of the CdS synthesized by the sonochemical method the nanorods are uniform and

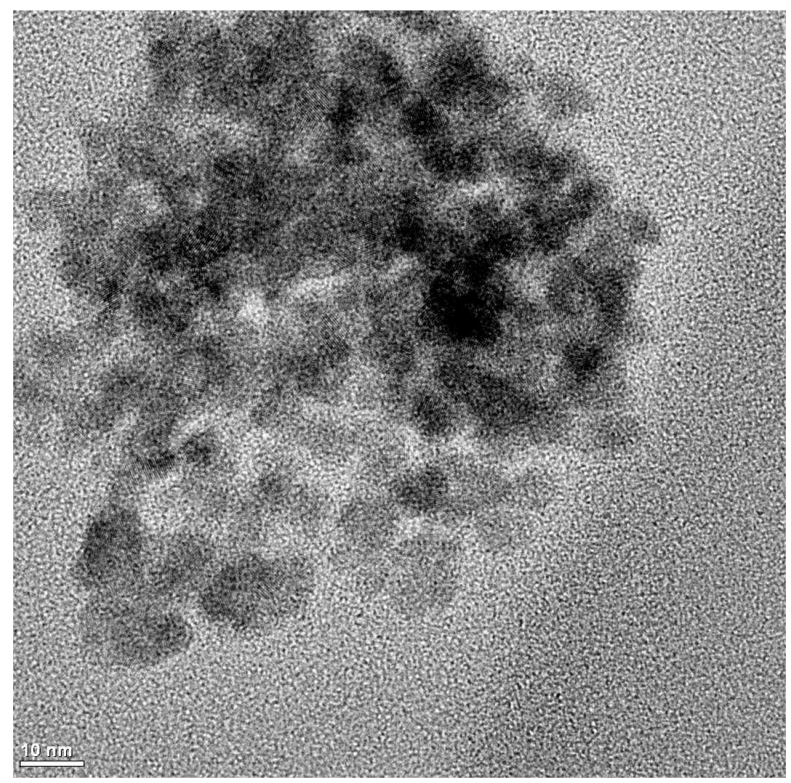

(a)

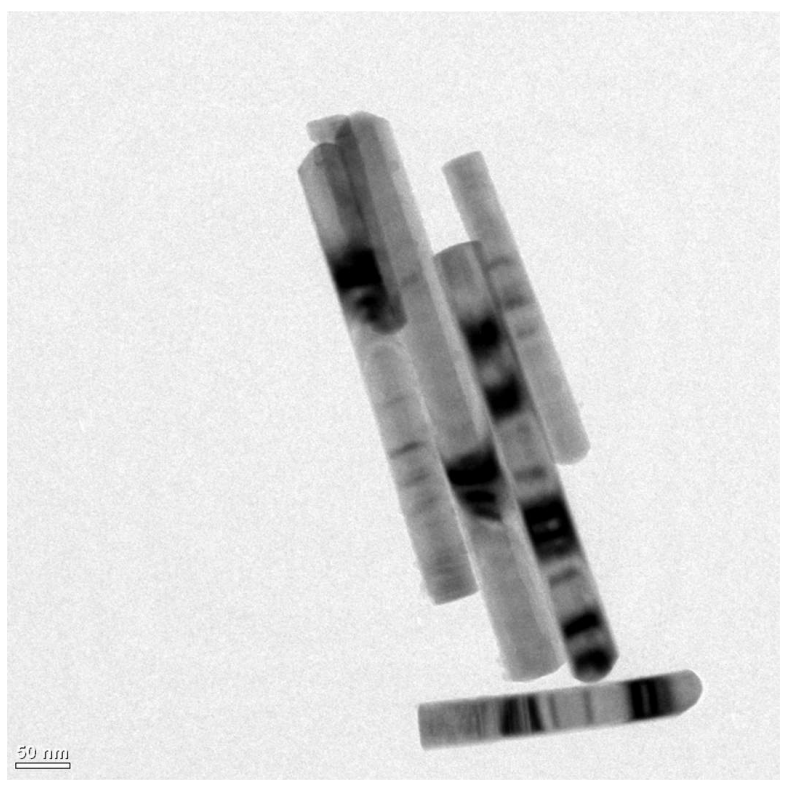

(b)

Fig. 2. TEM images of CdS nanoparticles synthesized with different methods (a) sonochemical method (Sample S1), (b) combined sonochemicalsolvothermal method (Sample S6).

separated with a single crystalline hexagonal structure, which is consistent with the XRD results.

The EDX spectra of the CdS nanoparticles synthesized using the two different methods are shown in Fig. 3. The spectrum of CdS synthesized 
by the combined method (Sample S6) indicates the presence of $\mathrm{Cd}$ and $\mathrm{S}$ with a $\mathrm{Cd}: \mathrm{S}$ ratio of approximately 1.00:1.10. Both the XRD and EDX analysis results verify the $\mathrm{CdS}$ nanoparticles to be pure in nature.

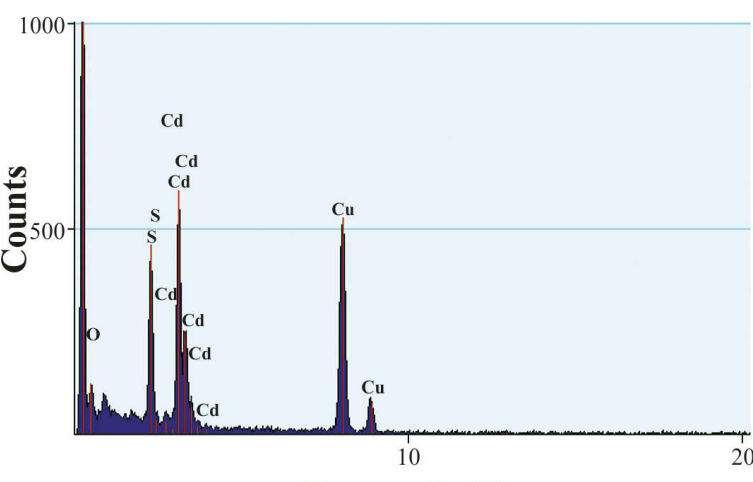

Energy [keV]

(a)

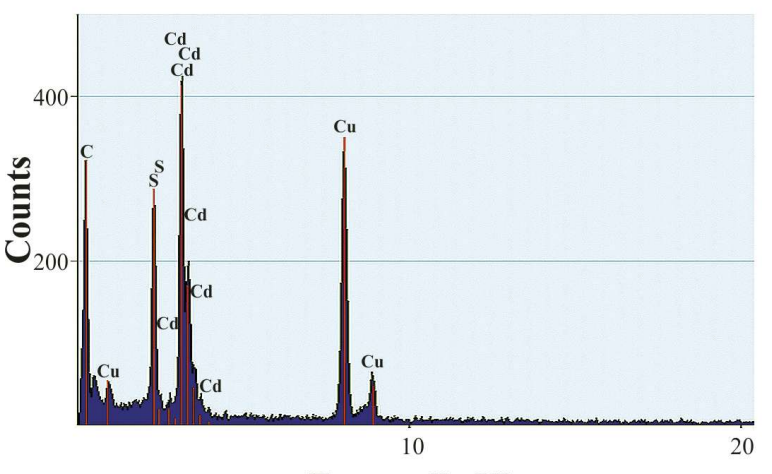

Energy [keV]

(b)

Fig. 3. EDX spectrum of CdS nanoparticles synthesized with different methods (a) sonochemical method (Sample S1), (b) combined sonochemicalsolvothermal method (Sample S6).

A schematic representation of the effect of experimental procedure on structural development is shown in Fig. 4.

Ultrasonic waves are intense enough to produce cavitation, which can produce the driving force for initiation and completion of chemical reactions, such as oxidation, reduction, dissolution, decomposition and hydrolysis [14]. Cavitation acts through concentrating the ultrasonic energy into a localized spot where high temperature, high pressure and very short lifetimes are achieved [21]. These

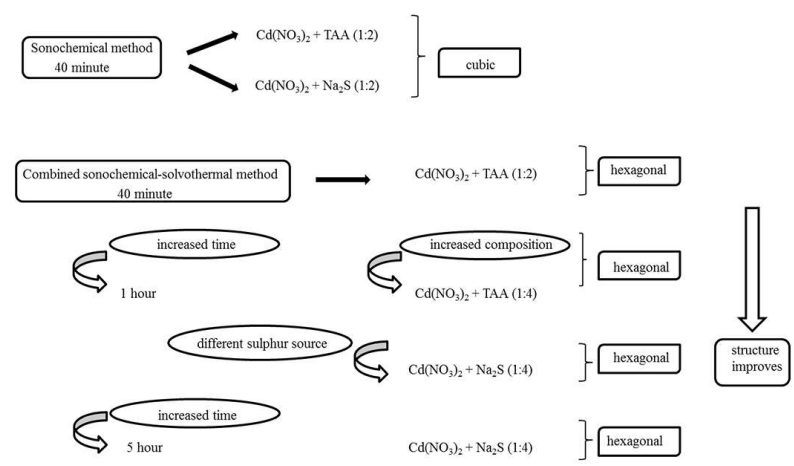

Fig. 4. Schematic presentation and structural development of synthesized CdS nanoparticles obtained using different experimental procedures.

extreme conditions obtained during bubble collapse have been used to decompose the chemical bonds of chemical species and provide ions for formation of novel nanoparticles.

The suggested formation mechanism of $\mathrm{CdS}$ nanoparticles in the sonochemical method can be summarized as follows:

$$
\begin{aligned}
\left.\left.\mathrm{H}_{2} \mathrm{O}()\right)\right) & \rightarrow \mathrm{OH} \bullet+\mathrm{H} \bullet \\
2 \mathrm{H} \bullet+\mathrm{CH}_{3} \mathrm{CSNH}_{2} & \rightarrow \mathrm{H}_{2} \mathrm{~S}+\mathrm{CH}_{3} \mathrm{CNH}_{2} \\
\mathrm{Cd}^{+2}+\mathrm{H}_{2} \mathrm{~S} & \rightarrow \mathrm{CdS}+2 \mathrm{H} \bullet
\end{aligned}
$$

Reaction 1 indicates the primary products of water sonication to form $\mathrm{H} \bullet$ and $\mathrm{OH} \bullet$ radicals within the collapsing gas bubble [22]. Reaction 2 indicates the formation of $\mathrm{H}_{2} \mathrm{~S}$ via hydrogen radicals and the $\mathrm{H}_{2} \mathrm{~S}$ combines with $\mathrm{Cd}^{+2}$ according to the reaction 3 to yield $\mathrm{CdS}$ nanoparticles.

The ultrasonic irradiation in the presence of TAA and water produces $\mathrm{H}_{2} \mathrm{~S}$ gradually. As the Gibbs free energy of the surface is usually quite high due to a large surface/volume ratio, freshly formed $\mathrm{CdS}$ nanoparticles have a tendency to aggregate on a support to become stable [23]. In the above suggested formation mechanism $\mathrm{H}_{2} \mathrm{~S}$ is gradually released preventing the rapid reaction between $\mathrm{S}^{-2}$ and $\mathrm{Cd}^{+2}$, thus restricting the growth of $\mathrm{CdS}$ nanoparticles. 
In case of nanorod synthesis using the combined method a modified reaction pathway has been suggested in 5 steps as shown below.

$$
\begin{gathered}
\left.\left.\left.\mathrm{H}_{2} \mathrm{O}\right)\right)\right) \text { } \rightarrow \mathrm{OH} \bullet+\mathrm{H} \bullet \\
\mathrm{Na}_{2} \mathrm{~S} \rightarrow 2 \mathrm{Na}^{+}+\mathrm{S}^{-2} \\
\mathrm{Cd}\left(\mathrm{NO}_{3}\right)_{2} \rightarrow \mathrm{Cd}^{+2}+2 \mathrm{NO}_{3}^{-} \\
\mathrm{Cd}^{+2}+\mathrm{Y}^{-2} \rightarrow \mathrm{CdY} \\
\mathrm{CdY}+\mathrm{S}^{-2} \rightarrow \mathrm{CdS}+\mathrm{Y}^{-2}
\end{gathered}
$$

Reaction 4 indicates the formation of $\mathrm{H} \bullet$ and $\mathrm{OH} \bullet$ radicals from the ultrasonic irradiation of water. Reaction 5 and reaction 6 indicate the formation of $\mathrm{S}^{-2}$ and $\mathrm{Cd}^{+}$ions, respectively. Krishnan et al. [24] have suggested ethylenediamine $\left(\mathrm{Y}^{-2}\right)$ and $\mathrm{Cd}^{+2}$ to form a stable complex of $\mathrm{CdY}$ as shown in reaction 7. This complex gradually starts releasing cadmium ions into the solution, leading to the formation of $\mathrm{CdS}$ nanoparticles (reaction 8) due to interaction with the sulphur ions released through reaction 5 .

Ethylenediamine and ultrasonic irradiation play a critical role during the formation and growth of $\mathrm{CdS}$ nanoparticles. In the presence of ultrasonic waves, ethylenediamine captures the $\mathrm{Cd}^{+2}$ ions and prevents the agglomeration of the CdS nanoparticles by releasing $\mathrm{Cd}^{+2}$ ions gradually into the solution. The number of cadmium ions increases with increasing ultrasonication time, resulting in growth of the CdS nanorod size. Based on the morphology of the CdS structure (Fig. 2), the sulphur source was changed to $\mathrm{Na}_{2} \mathrm{~S}$ instead of TAA in the combined method due to the agglomeration effect resulting from the release of $\mathrm{H}_{2} \mathrm{~S}$ which reacted immediately with the cadmium ions when TAA was used. Also, an increase in the number of sulphur ions with increasing sodium sulphide precursor ratio resulted in improving the growth morphology of CdS nanoparticles.

\section{Conclusions}

CdS nanoparticles were synthesized by both sonochemical method and combined sonochemical-solvothermal method and the results were compared. Structure development revealed that the reaction time, type and ratio of the precursor, such as sulphur, source were considerable factors influencing the formation of $\mathrm{CdS}$ nanoparticles. Also, the growth mechanism of the synthesized CdS nanaoparticles by both sonochemical and sonochemical-solvothermal methods has been discussed.

The significant point of this work was the success of attaining uniform hexagonal $\mathrm{CdS}$ nanoparticles using the combined sonochemicalsolvothermal method. Moreover, the nanoparticles were single crystalline in nature with almost a structurally perfect single surface. Further optimization of this synthesis method is needed to improve the quality of these products. This method will enable us to develop and improve the synthesis of other nanostructural materials.

\section{References}

[1] LEE J.S., Physica E, 51 (2013), 94.

[2] Vidor F.F., Wirth G.I., Hilleringmann U., Microelectron. Reliab., 54 (2014), 2760.

[3] Godlewski M., Yatsunenko S., Nadolska A., Opalniska A., LOJKOWSKI W., TOMSIA K.D., Goldys E.M., Opt. Mater, 31 (2009), 490.

[4] Steigerwald M.L., Brus L.E., Accounts Chem. Res., 23 (1990), 183.

[5] Lee J., Sundar V.C., Heine J.R., Bawendi M.G., JENSEN K.F., Adv. Mater, 12 (2000), 1102.

[6] Diaz J.G., Planelles J., Langmuir, 20 (2004), 11278.

[7] Wang C., Ao Y., Wang P., Hou J., Qian J., ZHANG S., Mater. Lett., 64 (2010), 439.

[8] Xi Y., Hu C., Zheng C., Zhang H., Yang R., TiAn Y., Mater. Res. Bull., 45 (2010), 1476.

[9] Yan S., Sun L., Qu P., Huang N., Song Y., XIAO Z., J. Solid State Chem., 182 (2009), 2941.

[10] Zhang J., Yang Y., Jiang F., Li J., XU B., WANG S., WANG X., J. Cryst. Growth, 293 (2006), 236.

[11] ZHOU S.M., Mater. Lett., 61 (2007), 119.

[12] BiÇER M., AYdin A.O., ŞIŞMAN I., Electrochim. Acta, 55 (2010), 3749.

[13] Yang W., Wu Z., Lu Z., Yang X., Song L., Microelectron. Eng., 83 (2006), 1971.

[14] Suslick K.S., Ultrasound. Its Chemical, Physical, and Biological Effects, VCH Verlagsgesellschaft, Weinheim - Basel - Cambridge - New York, 1988. 
[15] Wang H., Zhu J.J., Ultrason. Sonochem., 11 (2004), 293.

[16] Motlagh M.K., Rahimi R., Kachousangi M.J., Molecules, 15 (2010), 280.

[17] Cui S., Xipeng P., Zhang D., Qian X., Gao Y., Mater. Sci. Forum, 694 (2011), 345.

[18] Krishnamoorthy K., Kim G.S., Kim S.J., Ultrason. Sonochem., 20 (2013), 644.

[19] Amiri O., MashKani S.M., Rad M.M., AbDVALI F., Superlattice. Microst., 66 (2014), 67.

[20] Matsumura M., Furukawa S., Saho Y., TsuboMURA H., J. Phys. Chem., 89 (1985), 1327.

[21] Suslick K.S., Hammerton D.A., Cline R.E., J. Am. Chem. Soc., 108 (1986), 5641.
[22] Okitsu K., Mizukoshi Y., Bandow H., Maedu Y., Yамамото T., Nagata Y., Ultrason. Sonochem., 3 (1996), 249.

[23] Rafati A.A., Borujeni A.A., Najafi M., HaJIAN A., J. Mol. Liq., 174 (2012), 124.

[24] Krishnan K., Plane R.A., Inorg. Chem., 5 (1966), 852.

Received 2016-04-04

Accepted 2016-07-11 